\title{
WHO draft guidelines on dietary saturated and trans fatty acids: time for a new approach?
}

Article

Published Version

Astrup, A., Bertram, H. C. S., Bonjour, J.-P., de Groot, L. C. P., de Oliveira Otto, M. C., Feeney, E. L., Garg, M. L., Givens, I., Kok, F. J., Krauss, R. M., Lamarche, B., Lecerf, J.-M., Legrand, P., McKinley, M., Micha, R., Michalski, M.-C., Mozaffarian, D. and Soedamah-Muthu, S. S. (2019) WHO draft guidelines on dietary saturated and trans fatty acids: time for a new approach? British Medical Journal, 366. 14137. ISSN 1468-5833 doi: https://doi.org/10.1136/bmj.I4137 Available at https://centaur.reading.ac.uk/84706/

It is advisable to refer to the publisher's version if you intend to cite from the work. See Guidance on citing.

To link to this article DOI: http://dx.doi.org/10.1136/bmj.l4137

Publisher: BMJ Publishing Group Ltd

All outputs in CentAUR are protected by Intellectual Property Rights law, including copyright law. Copyright and IPR is retained by the creators or other copyright holders. Terms and conditions for use of this material are defined in the End User Agreement. 


\section{www.reading.ac.uk/centaur}

\section{CentAUR}

Central Archive at the University of Reading

Reading's research outputs online 


\title{
WHO draft guidelines on dietary saturated and trans fatty acids: time for a new approach?
}

The 2018 WHO draft guidance on fatty acids fails to consider the importance of the food matrix, argue Arne Astrup and colleagues

\author{
Arne Astrup head of department ${ }^{1}$, Hanne CS Bertram professor ${ }^{2}$, Jean-Philippe Bonjour honorary \\ professor of medicine ${ }^{3}$, Lisette CP de Groot professor ${ }^{4}$, Marcia C de Oliveira Otto assistant \\ professor $^{5}$, Emma L Feeney assistant professor ${ }^{6}$, Manohar L Garg director ${ }^{7}$, lan Givens professor \\ and director ${ }^{8}$, Frans $\mathrm{J}$ Kok emeritus professor of nutrition and health ${ }^{4}$, Ronald M Krauss senior \\ scientist and Dolores Jordan endowed chair ${ }^{9}$, Benoît Lamarche chair of nutrition ${ }^{10}$, Jean-Michel \\ Lecerf head of department ${ }^{11}$, Philippe Legrand professor ${ }^{12}$, Michelle McKinley reader ${ }^{13}$, Renata \\ Micha associate professor ${ }^{14}$, Marie-Caroline Michalski research director ${ }^{15}$, Dariush Mozaffarian \\ dean $^{14}$, Sabita S Soedamah-Muthu associate professor ${ }^{16}$
}

\footnotetext{
${ }^{1}$ Department of Nutrition, Exercise, and Sport, University of Copenhagen, Nørre Alle 51, DK-2200 Copenhagen N, Denmark; '²epartment of Food Science, Aarhus University, Denmark; ${ }^{3}$ Geneva University Hospitals and Faculty of Medicine, Switzerland; ${ }^{4}$ Division of Human Nutrition, Department of Agrotechnology and Food Sciences, Wageningen University, Netherlands; ${ }^{5}$ University of Texas Health Science Center at Houston, TX, USA; ${ }^{6}$ Institute of Food and Health, University College Dublin, Republic of Ireland; ${ }^{7}$ Nutraceutricals Research Programme, University of Newcastle, Callaghan, NSW 2308, Australia; ${ }^{8}$ Institute for Food, Nutrition, and Health, University of Reading, UK; ${ }^{9} \mathrm{Children}$ 's Hospital Oakland Research Institute and UCSF Benioff Children's Hospital, Oakland, CA, USA; ${ }^{10}$ Institute of Nutrition and Functional Foods, Université Laval, Québec, Canada; ${ }^{11}$ Nutrition et Activité Physique, Institut Pasteur de Lille, France; ${ }^{12}$ Agrocampus-INRA, Rennes, France; ${ }^{13}$ Institute for Global Food Security, Queen's University Belfast, UK; ${ }^{14}$ Friedman School of Nutrition Science and Policy, Tufts University, Boston, MA, USA; ${ }^{15}$ INRA, INSERM, Univ Lyon, Université Claude Bernard Lyon 1, CarMeN laboratory, CRNH Rhône-Alpes, Oullins, France; ${ }^{16}$ Center of Research on Psychology in Somatic Diseases (CORPS), Department of Medical and Clinical Psychology, Tilburg University, Netherlands
}

Key messages

The 2018 WHO draft guidelines on dietary saturated fatty acids and trans fatty acids recommend reducing total intake of saturated fat and replacing it with polyunsaturated and monounsaturated fatty acids

The recommendations fail to take into account considerable evidence that the health effects of saturated fat varies depending on the specific fatty acid and on the specific food source

Maintaining general advice to reduce total saturated fatty acids will work against the intentions of the guidelines and weaken their effect on chronic disease incidence and mortality

A food based translation of the recommendations for saturated fat intake would avoid unnecessary reduction or exclusion of foods that are key sources of important nutrients

Non-communicable diseases are the world's leading cause of death, responsible for $72 \%$ of the 54.7 million deaths in $2016 .{ }^{1}$ Cardiovascular diseases are responsible for approximately $45 \%$ of all deaths from non-communicable diseases, with modifiable risk factors such as diet, physical activity, smoking, and alcohol intake being major causes of disease.
Among dietary factors, the World Health Organization considers saturated fatty acids and trans fatty acids to be important. Consensus exists on the health benefits of eliminating industrially produced trans fatty acids- that it will reduce incidence of cardiovascular disease and mortality. ${ }^{2}$ Foods containing more than $2 \%$ total fat as trans fat were banned in Denmark in 2004, and similar legislation is soon to be implemented throughout the European Union. In the United States the Food and Drug Administration no longer considers industrial trans fats to be "generally regarded as safe."

Many governments consider WHO dietary guidelines to be state of the art scientific evidence, translating them into regional and national dietary recommendations. These guidelines have potential health implications for billions of people, so the consistency of the science behind such recommendations and the validity of the conclusions are crucial. Here, we look at the evidence linking saturated fat intake and cardiovascular risk and find that the WHO draft guidelines have excluded some important aspects and studies. 


\section{WHO draft guidelines}

WHO draft guidelines on dietary saturated and trans fatty acids for adults and children were published for consultation in May 2018. They recommend reducing intake of total saturated fatty acids to less than $10 \%$ of total energy consumption and replacing with polyunsaturated fat and monounsaturated fat to reduce incidence of cardiovascular disease and related mortality. ${ }^{2}$ But this fails to take into account considerable evidence that the health effects vary for different saturated fatty acids and that the composition of the food in which they are found is crucially important (box 1). ${ }^{4-6}$ Food composition has a substantial effect on lipid digestion, absorption kinetics, and postprandial lipaemia, ${ }^{3}$ which is an independent risk factor for cardiovascular disease. $^{7}$

\section{Box 1: Saturated fat in food products ${ }^{3}$}

Saturated fatty acids are found in a wide diversity of foods that vary in composition and structure, resulting in different physiological effects. Stearic acid in dark chocolate, palmitic acid in meat, and heptadecanoic acid in dairy products have completely different physiological effects. Moreover, the food matrix in which the fatty acids exist has major importance for these effects. Dairy products, for example, have very different compositions and milk fat structures. Full fat milk is a natural emulsion of fat globules enclosed in milk fat globule membrane, but when homogenised the fat droplets become much smaller and covered with proteins. Butter is a water in oil emulsion. Yoghurt is a fermented food containing live cultures, in which milk fat globules are dispersed in a gelled milk protein matrix. Cheese is one of the most complex dairy matrices. It is a fermented food containing live cultures, where fat is present in milk fat globules and sometimes as "free fat inclusions," in a solid present in milk fas matrix rich in milk proteins, calcium, and milk fat globule membrane. Ice cream contains a combination of crystallised fat globules around air bubbles and ice crystals in a liquid syrup phase.

Foods from other animal sources that contain saturated fatty acids also have a wide range of compositions and structures. Animal fats, such as lard and tallow, are $100 \%$ lipids. In unprocessed meat, lipids are mostly in adipocytes and intracellular lipid droplets of muscle. Processed meats can contain fat inclusions in a gelled protein matrix, free fat domains, and remnant adipocytes, depending on the type of processing. Egg yolk contains lipids structured as lipoproteins of both low and high density.

In processed foods such as pastries and biscuits (cookies) the fat inclusions (composed of palm oil, butter, or other fats) are embedded in a solid, carbohydrate matrix, often rich in sugar. Chocolate is composed of particles (sugar) and fermentation products from cocoa beans embedded in solid fat. Vegetable oils that are rich in saturated fatty acids, such as palm oil and coconut oil, are $100 \%$ lipids.

The saturated fatty acids in these different foods are also present as different types of lipid molecules-notably triglycerides and phospholipids. In these molecules, saturated fatty acids can be esterified at different positions depending on the source of fat.

\section{How robust is the evidence linking saturated fat to cardiovascular disease?}

\section{Evidence from randomised controlled trials with clinical endpoints}

Several recently published meta-analyses of observational studies and randomised controlled trials (RCTs) have found that total saturated fat is not associated with non-communicable diseases including coronary heart disease, cardiovascular disease, and all cause mortality. ${ }^{8-10}$ By contrast, a Cochrane analysis that included data from only 15 RCTs found an association between reduced intake of saturated fat and a decrease in the composite endpoint of cardiovascular events (relative risk $0.83,95 \%$ confidence interval 0.72 to 0.96 ). But it also found no significant association between reducing saturated fatty acids and total mortality $(0.97,0.90$ to 1.05$)$, cardiovascular disease mortality $(0.95,0.80$ to 1.12$)$, fatal and non-fatal myocardial infarction $(0.90,0.80$ to 1.01$)$, non-fatal myocardial infarction $(0.95,0.80$ to 1.13$)$, stroke $(1.00,0.89$ to $1.12)$, coronary heart disease events $(0.87,0.74$ to 1.03$)$, and coronary heart disease mortality $(0.98,0.84$ to 1.15$){ }^{11}$

\section{Evidence from randomised controlled trials with surrogate endpoints}

The WHO draft guidance relies heavily on a meta-analysis of 84 RCTs that tested the effect of modifying saturated fat intake on serum lipid and lipoprotein concentrations, including low density lipoprotein (LDL) cholesterol, and the ratio of total cholesterol to high density lipoprotein cholesterol. ${ }^{12}$ This approach — which focuses on total saturated fatty acids, ignores food sources, and uses surrogate endpoints-is problematic for several reasons.

First, not all saturated fatty acids are equal; the magnitudes and even directions of the effects on both surrogate and long term endpoints vary depending on fatty acid. Using the ratio of total cholesterol to high density lipoprotein cholesterol as a biomarker of cardiovascular disease risk, for example, is a problem because the ratios are different for lauric acid (12:0) myristic acid (14:0), palmitic acid (16:0), and stearic acid (18:0).$^{13}$ Moreover, high plasma concentrations of the heptadecanoic acid (17:0) are associated with a reduced risk of coronary heart disease. ${ }^{14}$ Thus, saturated fatty acids cannot be viewed as one homogeneous group with regard to effects of diet on disease risk.

Second, it is unclear whether the observed changes in serum lipoproteins translate into a reduction in cardiovascular endpoints and mortality regardless of food source. ${ }^{4}$ Most trials included in the meta-analysis did not investigate whole food sources of saturated fat. Instead, some studies compared the effect of diets supplemented with fats rich in saturated fatty acids, monounsaturated fat, or polyunsaturated fat (such as cocoa butter, olive oil, soybean oil, and dairy butter) and others used fats not commonly found in diets (such as synthetic fats high in myristic acid)..$^{12}$ The food matrix in which the fatty acids exist (box 1) might be more important for the effect on cardiovascular disease risk than the saturated fat content (see supplementary file online).

Third, the meta-analysis mainly used LDL cholesterol concentration as a marker for cardiovascular disease risk, which could lead to erroneous conclusions. The atherogenicity of LDL particles is determined by, among other things, size. Small and medium LDL particles show the strongest association with risk of cardiovascular disease, whereas large particles show no association. ${ }^{15}$ The rise in serum LDL cholesterol concentration from total saturated fat consumption has been linked to a parallel increase in particle size, so it might not translate into an increased risk of cardiovascular disease. ${ }^{16}$

The PURE study, which included over 100000 people, shows why a broader view of biomarkers of cardiovascular disease is needed to inform guidelines. It found that diets high in saturated fatty acids were associated not only with higher serum concentrations of LDL cholesterol, but also with higher concentrations of HDL cholesterol, lower concentrations of triglycerides, and a lower apolipoprotein B:apolipoprotein A ratio. ${ }^{17}$ The study also found that diets high in saturated fat were not associated with cardiovascular disease events, except for a lower risk of stroke. ${ }^{18}$ The relevance of this observation is confirmed by at least three randomised trials comparing diets with different fats on clinical endpoints. ${ }^{10} 1920$

Mediterranean-style diets were associated with a significant reduction in major cardiovascular disease events without any reduction in LDL cholesterol in the Lyon Diet Heart Study ${ }^{19}$ and in updated analyses of the PREDIMED trial, ${ }^{20}$ which both showed that LDL cholesterol concentration is not a valid biomarker for alterations in cardiovascular disease risk caused by dietary changes. 
Reanalysis of the Minnesota Coronary Experiment (a double blind randomised controlled trial that tested whether replacing saturated fat with polyunsaturated fat reduced coronary heart disease and death) also supports the claim that serum cholesterol is not a valid surrogate biomarker for cardiovascular disease risk when making dietary changes. ${ }^{10}$ Despite the finding that the polyunsaturated fat diet produced a $13 \%$ greater reduction in serum cholesterol than the saturated fat diet, there was no reduction in cardiovascular disease endpoints. ${ }^{10}$

The reanalysis found a $22 \%$ higher mortality for each 0.78 $\mathrm{mmol} / \mathrm{L}$ reduction in serum cholesterol caused by the polyunsaturated diet. ${ }^{10}$ A meta-analysis found that cholesterol lowering using polyunsaturated fat diets did not show any evidence of benefit on mortality from coronary heart disease $(1.13,0.83$ to 1.54$)$ or all cause mortality $(1.07,0.90$ to 1.27$){ }^{10}$

\section{Evidence from observational studies and food based analyses of cardiovascular disease risks}

The WHO draft guidelines exclude substantial evidence derived from observational studies and meta-analyses of prospective cohort studies. The guideline argues that the quality of evidence for relevant outcomes from such studies is lower than from analyses of RCTs and that it was not possible to assess the potential differential effects of replacing saturated fatty acids with different nutrients. But observational studies are valuable for assessing the association between saturated fat and long term endpoints, such as cardiovascular disease. ${ }^{8921}$

Observational studies are also useful for examining the foods consumed in people's diets rather than examining individual nutrients. Longstanding evidence indicates that the food matrix is more important than its fatty acid content for predicting the effect of a food on risk of coronary heart disease. This was the conclusion of an expert consensus panel, that some of us took part in, nearly 10 years ago. ${ }^{21}$ Ample food based studies have examined whether foods with high saturated fat content, which are likely to be consumer targets for the WHO recommendation, contribute to cardiovascular disease events and mortality (table 1). A recommendation to reduce intake of total saturated fat without considering specific fatty acids and food sources is not evidence based; will distract from other more effective food based recommendations; and might cause a reduction in the intake of nutrient dense foods that decrease the risk of cardiovascular disease, type 2 diabetes, other serious non-communicable diseases, malnutrition, and deficiency diseases and could further increase vulnerability to nutrient deficiencies in groups already at risk.

\section{Discussion}

To understand why the current misconceptions about saturated fat are so solidly anchored in major public health bodies, including WHO, we must consider the historical evolution of guidelines.

Up until the 1950s nutrition science focused on single nutrients, and major public health policies focused on deficiencies in micronutrients, leading to fortification of selected staple foods; for example, iodine in salt and vitamin $\mathrm{B}_{3}$ and iron in wheat flour and bread. ${ }^{4}$ Nutrition science then changed focus to policies for preventing chronic diseases such as cardiovascular disease in affluent countries, and the single nutrient approach was maintained. This was based mainly on cross country comparisons between saturated fat intake and cardiovascular disease mortality. The simple two step deductive reasoning that "dietary fat, and saturated fat in particular, increases serum cholesterol" and "serum cholesterol is a risk factor for coronary heart disease" led to the conclusion that all dietary fat, and saturated fat in particular, should be reduced to prevent cardiovascular disease. ${ }^{4}$ The US dietary guidelines published in 1980, and international guidelines ever since, have focused on reducing intake of saturated fat.

Guidelines have an immense effect on dietary advice for individuals and the production of ready to eat meals and meals served in restaurants. Historically, the focus on reducing saturated fat led to the proliferation of industrially produced food products low in fat, saturated fat, and cholesterol and to the dissemination of products based on technologies to replace saturated fat. One example is the production of margarine and spreads based on partial hydrogenation of vegetable oils, which increased the content of trans fatty acids from zero to up to $40 \%$ of total fat. ${ }^{34}$

The widespread consumption of trans fat is considered to have been responsible for $6 \%$ to $19 \%$ of all coronary heart disease events in the US in $2006^{35}$ and to have caused about 2700 deaths annually and loss of 570000 life years in the UK every year. ${ }^{36}$ Denmark banned trans fats in 2004, and analyses have attributed the subsequent larger decline in coronary heart disease mortality in Denmark than in other EU countries to the elimination of trans fat from foods. ${ }^{37}$

Scientific and policy missteps may have led to many unnecessary deaths globally, and lessons should be learned. We think that recommendations to reduce intake of total saturated fat without considering specific fatty acids and food sources are not based on evidence and will distract from other, more effective, food based recommendations. Recommendations to reduce saturated fat might cause a reduction in the intake of nutrient dense foods that are important for preventing disease and improving health. We're concerned that, based on several decades of experience, a focus on total saturated fat might have the unintended consequence of misleading governments, consumers, and industry towards promoting foods low in saturated fat but rich in refined starch and sugar.

The WHO guidelines on saturated fat should consider different types of fatty acids and, more importantly, the diversity of foods containing saturated fatty acids that might be harmful, neutral, or even beneficial in relation to major health outcomes. We strongly recommend a more food based translation of how to achieve a healthy diet and reconsideration of the draft guidelines on reduction in total saturated fatty acids.

Contributors and sources: This is a summary of an international collaboration in response to the WHO hearing in May 2018. AA made the first draft, but otherwise all the authors contributed equally, each addressing specific questions in their core areas of expertise. AA is guarantor of the article. AA is an expert in dietary prevention of obesity, type 2 diabetes, and cardiovascular disease and chaired the Danish Nutrition Council that produced the scientific reports that lead Denmark to ban industrial trans fat in foods in 2004, the first country in the world to do so. HCSB is an expert in metabolomics applied in food and nutrition research and vice chairman of the Nordic Metabolomics Society. J-PB is an expert in nutrition, with special emphasis on the role of dietary protein in combination with physical activity in the prevention of musculoskeletal disorders. LCPdeG is professor in nutrition and ageing, with due attention to older adults. Her research aims to identify dietary strategies that optimise nutritional health status to slow down or reverse the stages that precede ageing related pathologies to preserve functional health and quality of life. MCdeOO is an expert in nutritional and cardiometabolic epidemiology. She has designed and carried out investigations elucidating the role of dietary fat consumption and circulating fatty acids on mortality, cardiovascular disease, diabetes, and their underlying mechanisms in adult populations. ELF is assistant professor in the Institute of Food and Health at University College Dublin and formerly research programme manager at Food for Health Ireland, a dairy functional 
foods research centre. Her research interests include sensory evaluation, food consumption patterns, food structures, and their effect on human health. MLG is an expert in fatty acid nutrition; anti-inflammatory, anti-aggregatory and antioxidant effects of bioactive nutrients, dietary supplement, and functional foods. IG is a registered nutritional scientist with research based expertise in the association between dairy products and risk of cardiovascular diseases and type 2 diabetes and was a member of the group that first identified a beneficial association between dairy consumption and central arterial stiffness in a longitudinal study. FJK is emeritus professor in Nutrition and Health at Wageningen University, the Netherlands. He has been working on diet and health in Western, Asian, and African populations, looking at both undernutrition and overnutrition. He was dean of science at Wageningen University for several years. RMK is a fellow of the American Society of Nutrition and the American Heart Association (AHA), where he twice led publication of Dietary Guidelines for Healthy Americans. He was also the founding chair of the AHA council on nutrition, physical activity, and metabolism, and is a national spokesperson for the AHA. In addition, he has served on the committee on dietary recommended intakes for macronutrients and the committee on biomarkers of chronic disease of the US National Academy of Medicine (NAM), and was a reviewer for the NAM report on optimising the process for establishing the dietary guidelines for Americans. BL is chair of nutrition at Laval University in Québec City, Canada. He conducts translational research aimed at better understanding the effects of diet on cardiometabolic health from physiological, clinical, and public health perspectives. J-ML is an endocrinologist and a nutritionist. $\mathrm{He}$ is medical doctor in the internal medicine department of the University Hospital in Lille, France, and head of the nutrition department of Institut Pasteur de Lille, France. He is also expert for the French Agency for Food Safety and for the Haute Autorité de Santé, France. PL is an expert in saturated fatty acid function and metabolism and chaired the French panel for lipid guidelines in the Agence nationale de sécurité sanitaire de l'alimentation, de l'environnement et du travail. MM is an expert on the ability of dietary interventions (including supplements, foods, and whole dietary patterns) to modify nutritional status and risk of chronic disease, particularly diabetes and cardiovascular disease. RM is an expert in elucidating health effects of dietary habits, quantifying global consumption patterns, and evaluating the comparative effectiveness of nutrition sensitive interventions. M-CM is an expert in the effects of the supramolecular structures of dietary lipids in foods on postprandial metabolism and metabolic inflammation in the frame of dietary prevention of obesity, cardiovascular diseases, and type 2 diabetes. She has expertise in the structure-function relation of milk fat globules and proposed the concept of "fast versus slow lipid" structures. She is leader of the postprandial lipids and lipoproteins: regulations and functional impacts team in the CarMeN laboratory in Lyons, France. DM is a cardiologist and public health expert whose research aims to produce robust, high quality evidence on dietary priorities for cardiometabolic health, corresponding disease specific burdens, and effective policies to reduce these burdens, with research investigations spanning epidemiological studies, evidence syntheses, clinical trials, national and global demography, and policy analyses and implementation. SSS-M is a leading expert in clinical epidemiology and nutritional science, in the field of type 1 and 2 diabetes and cardiovascular diseases. Several original cohort analyses, systematic reviews, and meta-analyses on dairy products were led by her for which she obtained an international award.

Competing interests: We have read and understood BMJ policy on declaration of interests and declare the following: AA: has received financial support from Danish Dairy Foundation, Global Dairy Platform, Arla Foods Amba, Denmark, and European Milk Foundation for projects conducted at the University of Copenhagen exploring the effects of dairy fats and cheese consumption on human health. The European Milk Foundation (EMF) sponsored the Expert Symposium on the Dairy Matrix 2016, organised by AA and co-chaired by AA and IG. AA has received travel expenses and honorariums in connection with meetings and lectures from Danone, Arla Foods, EMF, and Global Dairy Platform. HCSB: through employment at Aarhus University, has received financial support for research activities from Arla Foods amba, the Danish Dairy Research Foundation, and Arla Food for Health (a consortium between Arla Foods amba, Arla Foods Ingredients Group P/S, Aarhus University and University of Copenhagen). J-PB: None. LCPdeG: None. MCdeOO: None. ELF: has received research funding from Food for Health Ireland, a dairy technology centre part financed by Enterprise Ireland and partly by dairy companies in Ireland. ELF has received speaking expenses from the National Dairy Council and the European Milk Forum. MLG: None. IG: Estonian BioCompetance Centre of Healthy Dairy Products, consultant to the Dairy Council on fats in dairy products and cardiometabolic disease; have received travel expenses and honorariums in connection with meetings and lectures from the Dairy Council, Dutch Dairy Association, Global Dairy Platform and the International Dairy Federation. FJK: None. RMK: Grant funding from Almond Board of California and Dairy Management. $\mathrm{BL}$ : chair of nutrition at Laval University, which is supported by private endowments from Pfizer, La Banque Royale du Canada, and Provigo-Loblaws. None of these organisations are involved in the research conducted by $\mathrm{BL}$ and his team. BL has received funding in the past five years from the Canadian Institutes for Health Research, the Natural Sciences and Engineering Research Council of Canada, Agriculture and Agri-Food Canada (Growing Forward programme supported by the Dairy Farmers of Canada, Canola Council of Canada, Flax Council of Canada, Dow Agrosciences), Dairy Research Institute, Dairy Australia, Merck Frosst, and Atrium Innovations. All support is investigator initiated, with no influence of the organisations in defining the research questions, in the process related to data analysis and interpretation, and publication of results. J-ML: Works for the Centre National Interprofessionnel de l'Économie Laitière (CNIEL), Yoplait, Syndifrais, Lactalis Alliance 4, LESAFFRE, member of scientific advisory board of Agence pour la Recherche et l'Information en Fruits et Légumes, European Natural Soyfoods Association, Fédération Française des Industriels Charcutiers Traiteurs, Observatoire CNIEL des Habitudes Alimentaires, Institut Olga Triballat. PL: None. MM: Receipt of honorarium and travel expenses for presentations given at conferences organised by the Dairy Council for Northern Ireland and the European Milk Forum. RM: reports grants from NIH/NHLBI R01 HL130735, the Bill and Melinda Gates Foundation, and from Unilever, and personal fees from World Bank, outside the submitted work. M-CM: Paid consultancies for CNIEL (French Dairy Interbranch Sector) and for different food and dairy companies, research laboratory received funding from CNIEL (French Dairy Interbranch Sector), Sodiaal-Candia R\&D, Nutricia Research, Danone Research, and is co-supervisor of a PhD student seconded from Institut des Corps Gras (ITERG). Member of the scientific committee of ITERG (non-financial interest). DM: Research funding from the National Institutes of Health and the Gates Foundation; personal fees from GOED, Nutrition Impact, Pollock Communications, Bunge, Indigo Agriculture, Amarin, Acasti Pharma, Cleveland Clinic Foundation, America's Test Kitchen, and Danone; scientific advisory board, Elysium Health (with stock options), Omada Health, and DayTwo; and chapter royalties from UpToDate; all outside the submitted work. SSS-M: received funding from the Global Dairy Platform, Dairy Research Institute and Dairy Australia for a meta-analysis on cheese and blood lipids (2012) and a meta-analysis of dairy and mortality (2015). She received The Wiebe Visser International Dairy Nutrition Prize from the Dutch Dairy Association's (NZO) Utrecht Group. In 2017, a student's internship project was partly funded by the Dutch Dairy Organisation and Global Dairy Platform.

Provenance: Not commissioned; externally peer reviewed.

1 GBD 2016 Causes of Death Collaborators. Global, regional, and national age-sex specific mortality for 264 causes of death, 1980-2016: a systematic analysis for the Global Burden of Disease Study 2016. Lancet 2017;390:1151-210.

10.1016/S0140-6736(17)32152-9 28919116

2 World Health Organization. Draft guidelines on saturated fatty acid and trans-fatty acid intake for adults and children. Public Consultation May to June 2018. https://extranet.who. int/dataform/upload/surveys/666752/files/Draft\%20WHO\%20SFA-TFA\%20guidelines_ 04052018\%20Public\%20Consultation(1).pdf

3 Michalski MC, Genot C, Gayet C, etal. Steering Committee of RMT LISTRAL. Multiscale structures of lipids in foods as parameters affecting fatty acid bioavailability and lipid structures of lipids in foods as parameters affecting fatty acid bioavailability and lipid
metabolism. Prog Lipid Res 2013;52:354-73. 10.1016/j.plipres.2013.04.004. 23624223

4 Mozaffarian D, Rosenberg I, Uauy R. History of modern nutrition science-implications for current research, dietary guidelines, and food policy. BMJ 2018;361:k2392. 10.1136/bmj.k2392 29899124

5 Mozaffarian D, Forouhi NG. Dietary guidelines and health-is nutrition science up to the task?BMJ 2018;360:k822. 10.1136/bmj.k822 29549076

6 Forouhi NG, Krauss RM, Taubes G, Willett W. Dietary fat and cardiometabolic health: evidence, controversies, and consensus for guidance. BMJ 2018;361:k2139. 10.1136/bmj.k2139 29898882

7 Pirillo A, Norata GD, Catapano AL. Postprandial lipemia as a cardiometabolic risk factor. Curr Med Res Opin 2014;30:1489-503. 10.1185/03007995.2014.909394. 24673475

8 de Souza RJ, Mente A, Maroleanu A, etal . Intake of saturated and trans unsaturated fatty acids and risk of all cause mortality, cardiovascular disease, and type 2 diabetes: systematic review and meta-analysis of observational studies. BMJ 2015;351:h3978. 10.1136/bmj.h3978 26268692

9 Siri-Tarino PW, Sun Q, Hu FB, Krauss RM. Meta-analysis of prospective cohort studies evaluating the association of saturated fat with cardiovascular disease. Am J Clin Nutr 2010;91:535-46. 10.3945/ajcn.2009.27725 20071648 
10 Ramsden CE, Zamora D, Majchrzak-Hong S, etal . Re-evaluation of the traditiona diet-heart hypothesis: analysis of recovered data from Minnesota Coronary Experiment (1968-73). BMJ 2016;353:i1246. 10.1136/bmj.i1246. 27071971

11 Hooper L, Martin N, Abdelhamid A, Davey Smith G. Reduction in saturated fat intake for cardiovascular disease. Cochrane Database Syst Rev 2015;6:CD011737. 10.1002/14651858.CD011737 26068959

12 Mensink RP. Effects of saturated fatty acids on serum lipids and lipoproteins: a systematic review and regression analysis. 2016. https://www.who.int/nutrition/publications/ nutrientrequirements/sfa_systematic_review/en/.

13 Mensink RP, Zock PL, Kester AD, Katan MB. Effects of dietary fatty acids and carbohydrates on the ratio of serum total to HDL cholesterol and on serum lipids and apolipoproteins: a meta-analysis of 60 controlled trials. Am J Clin Nutr 2003;77:1146-55. 10.1093/ajcn/77.5.1146 12716665

14 Chowdhury R, Warnakula S, Kunutsor S, etal . Association of dietary, circulating, and supplement fatty acids with coronary risk: a systematic review and meta-analysis. Ann Intern Med 2014;160:398-406. 10.7326/M13-1788 24723079

15 Pichler G, Amigo N, Tellez-Plaza M, etal . LDL particle size and composition and incident cardiovascular disease in a South-European population: The Hortega-Liposcale Follow-up Study. Int J Cardiol 2018;264:172-8. 10.1016/j.jijcard.2018.03.128 29628276

16 Siri-Tarino PW, Chiu S, Bergeron N, Krauss RM. Saturated fats versus polyunsaturated fats versus carbohydrates for cardiovascular disease prevention and treatment. Annu Rev Nutr 2015;35:517-43. 10.1146/annurev-nutr-071714-034449. 26185980

17 Mente A, Dehghan M, Rangarajan S, etal. Prospective Urban Rural Epidemiology (PURE) study investigators. Association of dietary nutrients with blood lipids and blood pressure in 18 countries: a cross-sectional analysis from the PURE study. Lancet Diabetes Endocrinol 2017:5:774-87. 10.1016/S2213-8587(17)30283-8 28864143

18 Dehghan M, Mente A, Zhang X, etal. Prospective Urban Rural Epidemiology (PURE) study investigators. Associations of fats and carbohydrate intake with cardiovascular disease and mortality in 18 countries from five continents (PURE): a prospective cohor study. Lancet 2017;390:2050-62. 10.1016/S0140-6736(17)32252-3 28864332

19 de Lorgeril M, Renaud S, Mamelle N, etal . Mediterranean alpha-linolenic acid-rich diet in secondary prevention of coronary heart disease. Lancet 1994;343:1454-9. 10.1016/S0140-6736(94)92580-1 7911176

20 Estruch R, Ros E, Salas-Salvadó J, etal. PREDIMED Study Investigators. Primary prevention of cardiovascular disease with a mediterranean diet supplemented with extra-virgin olive oil or nuts. N Engl J Med 2018;378:e34. 10.1056/NEJMoa1800389 29897866

21 Astrup A, Dyerberg J, Elwood P, etal . The role of reducing intakes of saturated fat in the prevention of cardiovascular disease: where does the evidence stand in 2010? Am J Clin Nutr 2011;93:684-8. 10.3945/ajcn.110.004622 21270379

22 Rong Y, Chen L, Zhu T, etal . Egg consumption and risk of coronary heart disease and stroke: dose-response meta-analysis of prospective cohort studies. BMJ 2013;346:e8539 10.1136/bmj.e8539 23295181

23 Geiker NRW, Larsen ML, Dyerberg J, Stender S, Astrup A. Egg consumption, cardiovascular diseases and type 2 diabetes. Eur J Clin Nutr 2018:72:44-56. 10.1038/ejcn.2017.153 28952608
24 Fuller NR, Sainsbury A, Caterson ID, etal . The effect of a high-egg diet on cardiometabolic risk factors in people with type 2 diabetes: the DIABEGG study-randomized weight loss and follow-up. Am J Clin Nutr 2018;107:921-31. 10.1093/ajcn/nqy048 29741558

25 Buitrago-Lopez A, Sanderson J, Johnson L, etal . Chocolate consumption and cardiometabolic disorders: systematic review and meta-analysis. BMJ 2011;343:d4488. 10.1136/bmj.d4488. 21875885

26 Larsson SC, Åkesson A, Gigante B, Wolk A. Chocolate consumption and risk of myocardial infarction: a prospective study and meta-analysis. Heart 2016;102:1017-22. 10.1136/heartjnl-2015-309203. 26936339

27 Gianfredi V, Salvatori T, Nucci D, Villarini M, Moretti M. Can chocolate consumption reduce cardio-cerebrovascular risk? A systematic review and meta-analysis. Nutrition 2018;46:103-14. 10.1016/j.nut.2017.09.006. 29290347

28 de Goede J, Soedamah-Muthu SS, Pan A, Gijsbers L, Geleijnse JM. Dairy consumption and risk of stroke: a systematic review and updated dose-response meta-analysis of prospective cohort studies. J Am Heart Assoc 2016;5:e002787. 10.1161/JAHA.115.002787. 27207960

29 Guo J, Astrup A, Lovegrove JA, Gijsbers L, Givens DI, Soedamah-Muthu SS. Milk and dairy consumption and risk of cardiovascular diseases and all-cause mortality: dose-response meta-analysis of prospective cohort studies. Eur J Epidemio 2017;32:269-87. 10.1007/s10654-017-0243-1. 28374228

30 Astrup A. Yogurt and dairy product consumption to prevent cardiometabolic diseases: epidemiologic and experimental studies. Am J Clin Nutr 2014;99(Suppl):1235S-42S. 10.3945/ajcn.113.073015 24695891

31 Thorning TK, Bertram HC, Bonjour JP, etal. Whole dairy matrix or single nutrients in assessment of health effects: current evidence and knowledge gaps. Am J Clin Nutr 2017:105:1033-45. 10.3945/ajcn.116.151548. 28404576

32 Micha R, Wallace SK, Mozaffarian D. Red and processed meat consumption and risk of incident coronary heart disease, stroke, and diabetes mellitus: a systematic review and meta-analysis. Circulation 2010;121:2271-83. 10.1161/CIRCULATIONAHA.109.924977 2047915

33 O'Connor LE, Kim JE, Campbell WW. Total red meat intake of $\geq 0.5$ servings/d does not negatively influence cardiovascular disease risk factors: a systemically searched meta-analysis of randomized controlled trials. Am J Clin Nutr 2017;105:57-69. 10.3945/ajcn.116.142521 27881394

34 Stender S, Dyerberg J, Astrup A. High levels of industrially produced trans fat in popular fast foods. N Engl J Med 2006;354:1650-2. 10.1056/NEJMc052959 16611965

35 Mozaffarian D, Katan MB, Ascherio A, Stampfer MJ, Willett WC. Trans fatty acids and cardiovascular disease. N Engl J Med 2006;354:1601-13 10.1056/NEJMra054035 16611951

36 Barton P, Andronis L, Briggs A, McPherson K, Capewell S. Effectiveness and cost effectiveness of cardiovascular disease prevention in whole populations: modelling study. BMJ 2011;343:d4044. 10.1136/bmj.d4044 21798967

37 Restrepo BJ, Rieger M. Denmark's policy on artificial trans fat and cardiovascular disease. Am J Prev Med 2016;50:69-76. 10.1016/.amepre.2015.06.018 26319518

Published by the BMJ Publishing Group Limited. For permission to use (where not already granted under a licence) please go to http://group.bmj.com/group/rights-licensing/ permissions 


\section{Table}

\section{Table 1| Nutrient dense foods that also contain substantial amounts of saturated fat}

\begin{tabular}{|c|c|c|}
\hline Food & Nutrients & Evidence linking food to cardiovascular disease and diabetes \\
\hline Eggs & $\begin{array}{c}13 \text { essential vitamins and minerals (eg, vitamin } D \text {, riboflavin, } \\
\text { iodine), high quality protein, a-linolenic acid ( } \mathrm{n}-3) \text {, lutein, } \\
\text { zeaxanthin, and choline }\end{array}$ & $\begin{array}{c}\text { No association with coronary heart disease, reduced risk of stroke. RCT data show } \\
\text { that two eggs a day has beneficial effects on cardiovascular disease biomarkers, }{ }^{22} 23 \\
\text { and improved glycaemic control in type } 2 \text { diabetes }{ }^{24}\end{array}$ \\
\hline $\begin{array}{l}\text { Dark } \\
\text { chocolate }\end{array}$ & $\begin{array}{l}\text { Stearic acid is the major saturated fat. Also rich in fibre, iron, } \\
\text { magnesium, potassium, phosphorus, zinc, and selenium. } \\
\text { Contains polyphenols, flavanols, and catechins. Contains } \\
\text { added sugar }\end{array}$ & $\begin{array}{c}\text { The WHO draft guidelines state that stearic acid has no harmful effect on "any } \\
\text { outcome assessed." Meta-analyses of observational evidence find dark chocolate } \\
\text { consumption to be associated with a substantial reduction in risk of cardiovascular } \\
\text { disease. }{ }^{2526} \text { RCTs find beneficial effects on cardiovascular disease biomarkers (HDL } \\
\text { and LDL cholesterol, blood pressure, etc) }{ }^{27}\end{array}$ \\
\hline Cheese & $\begin{array}{l}\text { Full fat cheese is high in medium and long chain saturated } \\
\text { fatty acids (C13:0, C20:0, C18:2t10c12, and C20:2n-6), a wide } \\
\text { diversity of typical bioactive fatty acids (conjugated linoleic } \\
\text { acid, phytanic acid, trans palmitoleic acid), protein, calcium, } \\
\text { magnesium, and lactic acid bacteria (that produce short chain } \\
\text { fatty acids), and has a complex matrix structure }\end{array}$ & $\begin{array}{l}\text { Meta-analyses of food based observational studies find that cheese intake is } \\
\text { associated with slightly reduced risk of cardiovascular disease. }{ }^{2829} \text { Mechanistic studies } \\
\text { and RCTs show that cheese intake has favourable effects on biomarkers of } \\
\text { cardiovascular disease (blood lipids and blood pressure) and that these effects cannot } \\
\text { be predicted based on content of total saturated fat and sodium }{ }^{30} 31\end{array}$ \\
\hline Meat & $\begin{array}{l}\text { Meat is a major source of high quality protein, bioavailable } \\
\text { iron, minerals, and vitamins, but is also a source of saturated } \\
\text { fat }\end{array}$ & $\begin{array}{l}\text { Meta-analyses of observational studies find that intake of processed meat, but not } \\
\text { red meat, is associated with a higher risk of coronary heart disease, which indicates } \\
\text { that processing or factors other than the saturated fat content are responsible for } \\
\text { any link to cardiovascular disease }{ }^{32} \mathrm{~A} \text { meta-analysis found no difference in } \\
\text { cardiovascular disease risk factors between groups with more and less than } 0.5 \text { daily } \\
\text { servings of meat }{ }^{33}\end{array}$ \\
\hline
\end{tabular}

